\title{
Factors Affecting the Surface Roughness in Sinking EDM Process
}

\author{
Ahmad Atif Fikri, a *, Maftuchin Romlie ${ }^{1}$, Aminnudin $^{1}$ \\ ${ }^{1}$ Department of Mechanical Engineering, Faculty of Engineering, Universitas Negeri Malang, Semarang Street No. 5, \\ Malang, East Java, Indonesia \\ Corresponding author : * atif.fikri.ft@um.ac.id
}

\begin{abstract}
The purpose of this study is to gain insights into the surface quality (smoothness) of sinking EDM machining products. Among other non-conventional machining processes, Electrical Discharge Machining $(\mathrm{EDM})$ is the most commonly used process. EDM is a machining process that uses electric sparks created between a workpiece and a tool (electrode). As a manufacturing process, EDM is used for workpieces which have intricate contours and precise dimensions, and works by using electric discharges (sparks) applied in a rapid series of repetitive electrical discharges between the two electrodes, separated by a dielectric fluid, and subject to an electric voltage. Since the tool tends to wear easily and the mould material is very hard and tough, it is necessary to keep within appropriate EDM machining parameters, so that the smoothness of the mould lives up to expectations. Therefore, the parameters of sinking EDM process should be well established to produce the expected results, i.e. the smoothest surface quality and the maximum removal rate. Regarding the electrode materials used, conducting a further experiment is required to achieve the appropriate settings of pulse current, on-time, off-time, servo voltage, and gap width. This experimental study involved several factors: (a) electrode material, (b) magnitude of current, (c) on-time, and (d) quality of surface (smoothness). In this study, the gap between the electrode and the workpiece was controlled at a distance of $40 \mu \mathrm{m}$, and with an off-time of 5 seconds, the same dielectric fluid, the same flow speed and the same dielectric immersion, and using the workpiece (AISI P20M steel). Quantitative approaches ( $\mathrm{t}$ test, one-way, and ANOVA) were applied to analyse the results of comparison test and to determine the best parameter in sinking EDM process.
\end{abstract}

Copyright (C) 2017Journal of Mechanical Engineering Science and Technology All rights reserved

Keywords: EDM process, Electrode, Surface Roughness

\section{Introduction}

The development of manufacturing technology is growing rapidly along with the need to improve human welfare. Means of transportation such as motorcycles, home appliances, and communications devices such as cellular telephone, both made of metal or other materials (plastic and composite), are advancing. The development speed has been greatly influenced by the availability of supported technology, such as machining, formation, and moulding technology.

The oldest machining process is the one performed by removing material in the form of chips. In metallic materials machining, the most used tools are lathes, freis, saws, grinders, etc, whereas in non-metal machining, the process is done by casting, forming, and moulding. Therefore, in mass manufacturing industry (casting, forming and moulding), the process of producing moulds, particularly the ones made of metal (both ferrous and non-ferrous), should be faster and efficient. The durability of mould is strongly influenced by the mechanical properties of metal as the moulding material. Materials that have a high resistance to a wide range of requirements are typically made of hard materials but with low machining capabilities. In other words, the production capability of the machine is very low, because it is beyond the machine's capacity to work with much stronger cutting tools. Furthermore, workpieces with difficult and intricate contours are no longer able to be processed with any conventional machine, or even with the most advanced CNC milling machine.

Non-conventional machines such as chemical machining, electrochemical machining, electrical discharge machining, and high energy beam machining, are intended to manufacture products with intricate and complex contours. One of the four types of non-conventional machines owned by the Department of Mechanical Engineering, Universitas Negeri Malang, is the electrical discharge machining (EDM), namely sinking EDM. According to Schey (2009) [1], the surface quality of 
EDM products is determined by many factors; the surface becomes rougher if the current density is higher, the viscosity of the dielectric material is higher, and the frequency is lower. These parameters highly depend on the enabled settings in the machine's features. There are various metals with different mechanical properties which can be used as a workpiece for intended purposes.

EDM is capable of handling the mechanical properties of metals, in terms of hardness, tensile strength, and toughness under static and dynamic loads. EDM process is used in mould-making, thus surface smoothness is prioritised. In conventional machining process, the roughness level is determined by the established parameters in the machine's system and the type of cutting tool used, thus the desired degree of smoothness is more achievable. While in EDM process, the factors affecting results are very complex, because the metal etching process involves heat generated by electric sparks, frequency of current discharge (on-current), level of cathode electrical conductivity (cutting tool), dielectric material, and mechanical properties of the workpiece (melting point). Dewangan (2010) [2], through his study on the steel AISI P20, concluded that the forming tool (cathode) wear was affected by the amount and frequency of current discharge, and the diameter of the forming tool. The fact that forming tool wear occurred showed how the factors affecting the surface smoothness of the mould were becoming more complex.

The forming tool materials that can be used in EDM are copper, brass, and graphite. These materials are more easily formed using a machine with a simple cutting tool (HSS material), thus the desired shape or dimension can be very easily achieved. A research conducted by Kumar et al. (2012) [3] found that silver electrode provided a better performance in certain characteristics, but was relatively costly. Thus, graphite electrode was preferable in terms of metal removal rate (MRR) since its cost was comparatively lower than copper. The EDM machining parameters examined were fixed distance control variable between the electrode and the workpiece, positive polarisation (electrode connected to the positive pole), and the use of dielectric available in the market. The research only focused on volume8 reduction speed, not on surface quality (smoothness).

A mould is (usually) made of hard solid steel which has an intricate contour and thus very difficult to process with a conventional machine. Consequently, the use of non-conventional machines, one of which is EDM, is more suitable for mould-making. The value of material removal rate and level of surface roughness of sinking EDM products depend on several parameters, such as pulse current, on- and off-time, servo voltage, and gap width. The bigger the value of pulse and gap width and the smaller the value of off-time and servo voltage, the higher the material removal will rate. If the value of pulse and width gap is big, and the value of off-time and servo voltage is too small, then the surface of the products will be rough [4].

The fact that cutting tool wear occurs and mould material is very hard and tough, denotes that it is necessary to utilise appropriate EDM machining parameters so that the surface quality of mould lives up to expectations [5]. Therefore, the parameters of sinking EDM process should be well established to produce the expected results, i.e. the smoothest surface quality and the maximum removal rate. Regarding the electrode materials used, conducting a further experiment is required to achieve the appropriate settings of the pulse current, on-time, off-time, servo voltage, and gap width.

\section{A. Determining Factors in the Ease of EDM Process}

The machining factors affecting the EDM machines differ from the conventional ones. Conventional machines rely on the hardness of tools and workpieces, whereas EDM machines depend on $\lambda$ (thermal conductivity) $\theta$ (melting point) and $\rho$ (electrical resistivity) [6]. The machining time cannot be considered as a parameter for the ease of EDM process because there are many other relatively complex factors affecting it, such as adhesion, cavitation, and short-circuiting [6].

\section{Method}

This experimental study was done to investigate the quality of surface roughness of sinking EDM machining products. The variables involved in this study were (a) magnitude of current, (b) forming tool materials, (c) length of the current release time and (d) level of roughness.

\section{A. Tool, Workpiece, And Data Analysis Technique}

Electrode materials used were: (a) copper, (b) brass, and (c) graphite. The workpiece materials used were the ones for manufacturing plastic moulds, namely Assab Steel 618 SUPREME, AISI 
P20M Steel (chemical composition: C 12:37\%, Cr 2:00\%, Mo 12:20\%, Mn 1.4\%, Si 0.3\%, Ni 1.0\%, and $\mathrm{S}<\mathrm{a} 0.01 \%$ ). These materials were utilised for injection moulding, extrusion dies, and forming tools.

The forming tool specimen was prepared in the workshop at the Department of Mechanical Engineering, Universitas Negeri Malang. The apparatus utilised were an EDM machine (C-TEK ZNC-320-50A), a vertical Freis machine for manufacturing forming tools (cathode), a surface grinding machine to smooth the workpiece surface, and a roughness measuring tool (Mitutoyo Portable Surface Roughness Tester SJ-301P).

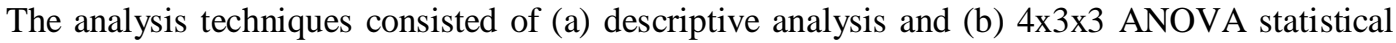
analysis integrated with the assumption tests: (1) the normality of distribution and (2) homogeneity of variance. The analysis was performed using a relevant computer programme.

\section{Findings and discussion}

The data obtained from the experiments in this study are presented in Table 1 . The results of the descriptive analysis are shown in Table 2 , and the ones of $4 \times 3 \times 3$ ANOVA statistical analysis are shown in Table 3.

Table 1. Results of Roughness Testing ( $\mu \mathrm{m})$

\begin{tabular}{|c|c|c|c|c|c|c|c|}
\hline \multirow{2}{*}{ No } & \multirow{2}{*}{ Electrode } & \multirow{2}{*}{$\begin{array}{c}\text { Current } \\
\text { (A) }\end{array}$} & \multicolumn{4}{|c|}{ Time On (second) } & \multirow[t]{2}{*}{ Average } \\
\hline & & & 0.5 & 1 & 1.5 & 2 & \\
\hline & & 5 & 3.3 & 3.6 & 3.6 & 3.7 & 3.3 \\
\hline \multirow[t]{3}{*}{1} & Copper & 10 & 2.9 & 3.1 & 3.2 & 3.4 & 2.9 \\
\hline & & 15 & 2.1 & 2.3 & 2.7 & 2.9 & 2.1 \\
\hline & & 5 & 4.3 & 4.6 & 4.7 & 4.9 & 4.3 \\
\hline \multirow[t]{3}{*}{2} & Brass & 10 & 3.9 & 4.2 & 4.2 & 4.4 & 3.9 \\
\hline & & 15 & 3.1 & 3.4 & 3.7 & 4.9 & 3.1 \\
\hline & & 5 & 8.3 & 8.6 & 8.7 & 8.9 & 8.3 \\
\hline \multirow[t]{3}{*}{3} & Graphite & 10 & 8.9 & 8.2 & 8.2 & 8.4 & 8.9 \\
\hline & & 15 & 8.1 & 8.4 & 7.7 & 8.9 & 8.1 \\
\hline & Average & & 4.54 & 4.74 & 4.82 & 5.24 & \\
\hline
\end{tabular}

Table 2. Results of Data Analysis

\begin{tabular}{|c|c|c|c|c|c|c|}
\hline No & Electrode & $\begin{array}{l}\text { Current } \\
\text { (A) }\end{array}$ & Average & Median & Mode & $\begin{array}{l}\text { Standard } \\
\text { Deviation }\end{array}$ \\
\hline \multirow{3}{*}{1} & \multirow{3}{*}{ Copper } & 5 & 3.3 & 3.6 & 3.6 & 0.15 \\
\hline & & 10 & 2.9 & 3.15 & \#N/A & 0.180277564 \\
\hline & & 15 & 2.1 & 2.5 & \#N/A & 0.316227766 \\
\hline \multirow{3}{*}{2} & \multirow{3}{*}{ Brass } & 5 & 4.3 & 4.65 & \#N/A & 0.216506351 \\
\hline & & 10 & 3.9 & 4.2 & 4.2 & 0.178535711 \\
\hline & & 15 & 3.1 & 3.55 & \#N/A & 0.683282518 \\
\hline \multirow{3}{*}{3} & \multirow{3}{*}{ Graphite } & 5 & 8.3 & 8.65 & \#N/A & 0.216506351 \\
\hline & & 10 & 8.9 & 8.3 & 8.2 & 0.286138079 \\
\hline & & 15 & 8.1 & 8.25 & \#N/A & 0.438035387 \\
\hline
\end{tabular}


Table 3. Results of ANOVA

\begin{tabular}{ccccc}
\hline $\begin{array}{c}\text { Anova: Single Factor } \\
\text { SUMMARY }\end{array}$ & & & & \\
Groups & Count & Sum & Average & Variance \\
\hline Copper with a current of 5 A & 4 & 14.2 & 3.55 & 0.03 \\
Copper with a current of 10 A & 4 & 12.6 & 3.15 & 0.043333 \\
Copper with a current of 15 A & 4 & 10 & 2.5 & 0.133333 \\
Brass with a current of 5 A & 4 & 18.5 & 4.625 & 0.0625 \\
Brass with a current of 10 A & 4 & 16.7 & 4.175 & 0.0425 \\
Brass with a current of 15 A & 4 & 15.1 & 3.775 & 0.6225 \\
Graphite with a current of 5 A & 4 & 34.5 & 8.625 & 0.0625 \\
Graphite with a current of 10 A & 4 & 33.7 & 8.425 & 0.109167 \\
Graphite with a current of 15 A & 4 & 33.1 & 8.275 & 0.255833 \\
\hline
\end{tabular}

\section{ANOVA}

\begin{tabular}{ccccccc}
\hline Source of Variation & $\boldsymbol{S S}$ & $\boldsymbol{d f}$ & $\boldsymbol{M S}$ & $\boldsymbol{F}$ & $\boldsymbol{P}$-value & $\boldsymbol{F}$ crit \\
\hline Between Groups & 196.815 & 8 & 24.60188 & 162.6073 & $8.45 \mathrm{E}-21$ & 2.305313 \\
Within Groups & 4.085 & 27 & 0.151296 & & & \\
& & & & & & \\
Total & 200.9 & 35 & & & & \\
\hline
\end{tabular}

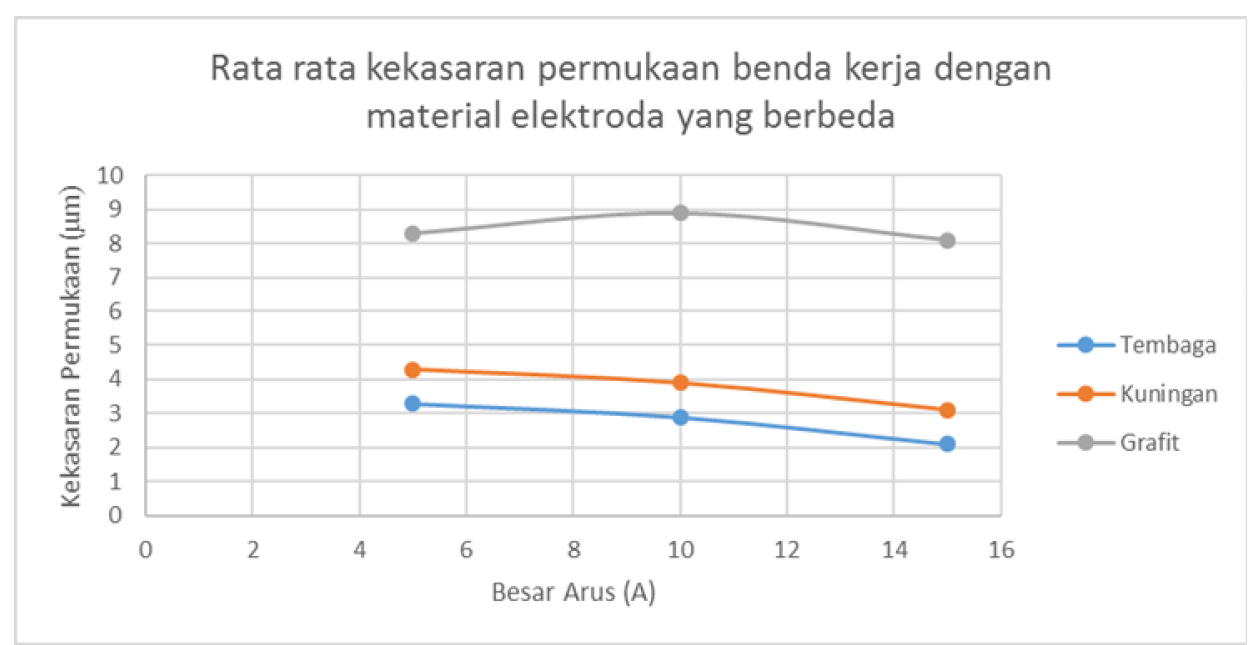

Fig. 1.The Average Roughness Level of Workpieces with Different Electrode Materials

The ANOVA test yielded a p-value of $8.45 \mathrm{E}-21$. This value indicates that this research result was not obtained by chance but as a result of significantly tested variables.

Figure 1 illustrates the results of surface roughness testing on workpieces with three different materials. The electrode made of graphite had the highest surface roughness value while copper had the lowest value. This result appears to be supported by previous research by Mahardika (2007) [6], which suggested that there were at least three important factors affecting the EDM machining process, i.e. $\lambda$ (thermal conductivity), $\theta$ (melting point), and $\rho$ (electrical resistivity). The detail of electrode properties used in this study is presented in Table 4.

Table 4. Properties of Electrodes Used in the Experiment 


\begin{tabular}{ccccc}
\hline No & Material & $\boldsymbol{\lambda}(\mathbf{W} / \mathbf{m K})$ & $\boldsymbol{\theta}(\mathbf{K})$ & $\boldsymbol{\rho}(\boldsymbol{\Omega} \mathbf{~ c m})$ \\
\hline 1 & Copper & 401 & 1356 & 0.0000017 \\
2 & Brass & 109 & 1173 & 0.000007 \\
3 & Graphite & 120 & 3565 & 0.0007837 \\
\hline
\end{tabular}

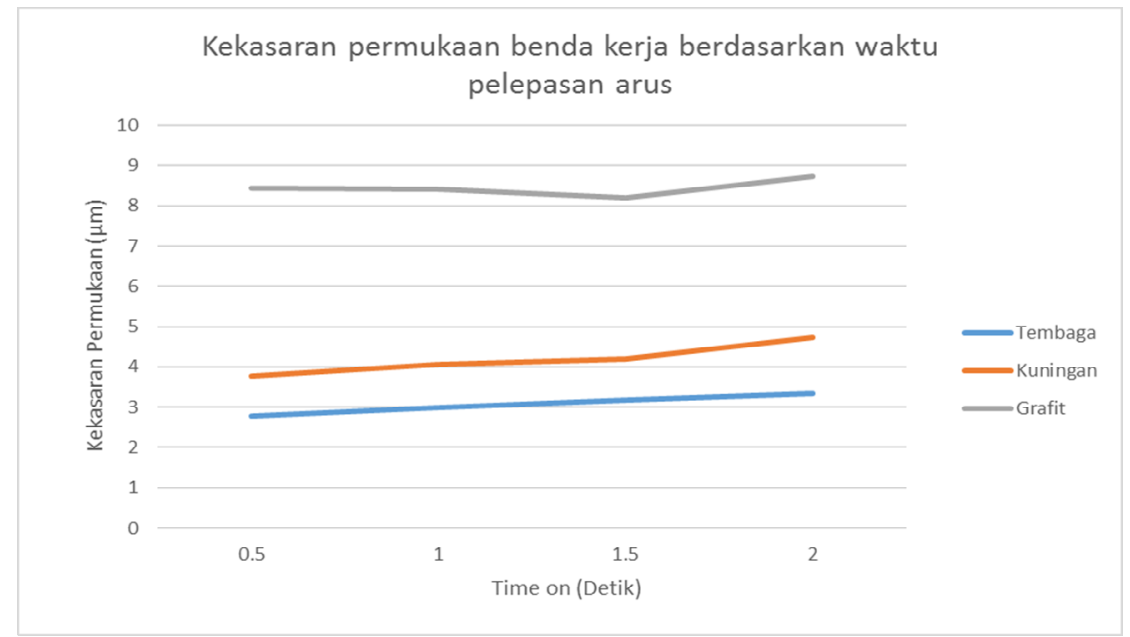

Fig. 2. Workpiece surface roughness based on current discharge rate

Graphite has the highest value of electrical conductivity, thus it requires a greater energy to cause a spark. As a result, this type of electron will hit the workpiece so strongly that it causes a deeper electron penetration, which eventually leads to an increase in roughness of the workpiece. Meanwhile, this aforementioned circumstance will not happen in electrodes made of copper and brass.

When it comes to the brass electrode, the energy needed for the electron to jump to the workpiece is relatively low because the electrical resistivity of brass is higher than graphite. As a result, the electron will hit the workpiece relatively weakly, hence the lower value of roughness.

Figure 2 shows that in addition to the types of electrodes used, the current discharge rate affects the roughness of the workpiece. The higher the current discharge rate is, the higher the discharge energy is released [7]. Thus, the beam of electrons will hit the workpiece harder so that the value of its surface roughness is higher.

\section{Conclusions}

Our work has led us to conclude that the types of electrode, the magnitude of current/the amount of pulse current, and material removal rate affect the surface roughness of the workpiece. Electrodes with properties $\lambda$ (thermal conductivity), $\theta$ (melting point) and $\rho$ (electrical resistivity) would affect the level of surface roughness of workpieces. The mechanism of the mechanical properties needs to be studied further to obtain information about electron behaviour related to its determining factors.

\section{References}

[1] J. A. Schey, Introduction to Manufacturing Processes, Yogyakarta: Andi, 2009

[2] S. K. Dewangan, "Experimental Investigation of Machining Parameters for EDM Using U- shaped Electrode of AISI P20 Tool Steel," Thesis. Department of Mechanical Engineering National Institute of Technology Rourkela, Rourkela, 2010.

[3] N. Kumar, L. Kumar, H. Tewatia and R. Yadav, "Comparative Study for MRR an Die-Sinking EDM Using Electode of Copper \& Graphite," International Journal of Advanced Technology \& Engineering Research (IJATER), vol. 2, 2012.

[4] Suhardjono, "Pengaruh Arc On dan Arc Off Time terhadap Kekasaran Permukaan dan Laju Pembuangan Geram Hasil Pemesinan Sinking EDM," Jurnal Teknik Mesin, vol. 6, no. 1, p. 14—19, 2004. 
[5] F. Han, C. Li, Y. Dingwen and Z. Xiaoguang, "Basic study on pulse generator for micro-edm," The International Journal of Advanced Manufacturing Technology, vol. 33, pp. 474-479, 2007.

[6] M. Mahardika, T. Tsujimoto and K. Mit, "A new approach on the determination of ease of machining by EDM processes," International Journal of Machine Tools \& Manufacture, no. 48, p. 746-760, 2008.

[7] M. Mahardika and K. Mitsui, "A new method for monitoring micro-electric discharge," International Journal of Machine Tools \& Manufacture, no. 48, p. 446-458, 2008 